\title{
A DESIGNAÇÃO DA SINGULARIDADE NO RESSOAR DO JOGO ENTRE A ESTRUTURA E O ACONTECIMENTO
}

\section{THE DESIGNATION OF SINGULARITY IN PLAY RESOUND BETWEEN THE STRUCTURE AND EVENT}

Sandro Braga

Patricia da Silva Meneghel

RESUMO: Neste artigo discute-se a noção de estrutura e de acontecimento aproximando as perspectivas teóricas propostas por Gilles Deleuze, Michel Pêcheux e Michel Foucault. Além da desses autores, a noção de estruturalidade, de Derrida, é empreendia para a sustentação do argumento de que para existir uma estrutura é preciso haver, antes, o que o autor chama condições para a existência da estrutura, que neste artigo está sendo tratada como arquiestrutura, condição não só para a instauração da estrutura como também do enunciado, do acontecimento e da singularidade. Para isso, percorre-se o percurso teórico-metodológico no intento de pontuar o ingresso da subjetividade na linguagem a partir da perspectiva enunciativa e a abertura para os estudos do discurso. Na sequência, apresenta-se a proposta central deste trabalho buscando-se mostrar como a singularidade é designada no acontecimento que tem como ponto de emergência o enunciado fruto do ressoar da estrutura determinante. As discussões apontam a singularidade como o efeito de real, materializada no enunciado a partir do ressoar entre a estrutura e o acontecimento. Em outros termos, a singularidade está justamente na efetivação do acontecimento, atualizando-o em um contínuo incessante, mas, por outro lado, evadindo-se dele e se prolongando a outros acontecimentos descontínuos.

PALAVRAS-Chave: Arquiestrutura. Estrutura. Acontecimento. Enunciado. Singularidade.

ABSTRACT: This article discusses about the notion of structure and event approaching the theoretical perspectives proposed by Gilles Deleuze, Pêcheux and Michel Foucault. In addition to these authors, the notion of structurality, Derrida, it undertook to support the argument that to be a structure there must be, first, what the author calls conditions for the existence of the structure, which in this article is being treated as arquiestrutura, condition not only for the 
establishment of the structure as well as the enunciation of the event and singularity. For that runs through the theoretical-methodological approach in an attempt to score the entry of subjectivity in language from the enunciative perspective and openness to discourse studies. Following, we present the central purpose of this study seeking to show how the singularity is designated in the event that has as an emergency point the enunciation fruit resound of determining structure. The discussions show the singularity as the actual effect embodied in utterance from the resonating between the structure and the event. In other words, the singularity is precisely the realization of the event, updating it in a ceaseless continuum, but on the other hand, absconding him and extending to other discontinuous events.

KEYWORDS: Arquiestrutura. Structure. Event. Enunciation. Singularity. 


\section{A DESIGNAÇÃO DA SINGULARIDADE NO RESSOAR DO JOGO ENTRE A ESTRUTURA E O ACONTECIMENTO}

\section{INTRODUÇÃO}

Este artigo tem o objetivo produzir uma reflexão em torno da questão da estrutura e do acontecimento, aproximando a perspectiva de Gilles Deleuze, em função da designação da singularidade que emana dos acontecimentos, efetuados na enunciação, à formulação proposta por Michel Pêcheux, no que toca à instauração da discursividade decorrente da ruptura de um sentido dado e a instauração de um sentido novo e, ainda, à proposição de Michel Foucault, que compreende o acontecimento como irrupção de uma singularidade histórica e, para quem, a investigação arqueogenealógica consiste em descrever e interpretar os fatos de discursos na trama da língua com a história, considerando que o discurso não move a história, mas é movido por ela e por seus dispositivos. Além desses autores, dialoga-se, também, com Derrida, quem defende que a possibilidade de instauração de uma estrutura está condicionada antes de tudo à possibilidade anterior dessa existência.

Para isso, recorre-se, ainda, às formulações acerca do enunciado e da enunciação, embasada nas formulações de Benveniste (1989, 2005), Foucault (2002) e Pêcheux (1997), considerando-se que os acontecimentos se atualizam em enunciados múltiplos. O foco deste trabalho está na estrutura que fundamenta e dá origem ao ressoar vibrante que atualiza um acontecimento.

A estrutura, compreendida por Deleuze (2009) como a convergência entre - pelo menos - duas séries heterogêneas, chamadas significante e significada, passa a ter sua existência marcada a partir do momento em que se relaciona e se instaura discursivamente, no enunciado, determinando um acontecimento. 
Segundo Deleuze, uma estrutura comporta sempre duas distribuições de pontos singulares que correspondem a séries de base. "Eis por que é inexato opor a estrutura e o acontecimento: a estrutura comporta um registro de acontecimentos ideais, isto é, toda uma história que lhe é interior. (2009, p.53, grifos do autor).

Portanto, o acontecimento é aqui entendido no campo das possibilidades (do devir do enunciado), ou seja, em um campo de efetuação de uma dada atualização, produzida pelo movimento dinâmico e transcendente de um significante e de um significado.

A figura 1, a seguir, demonstra graficamente a atualização de um acontecimento:

Figura 1 - A atualização do acontecimento

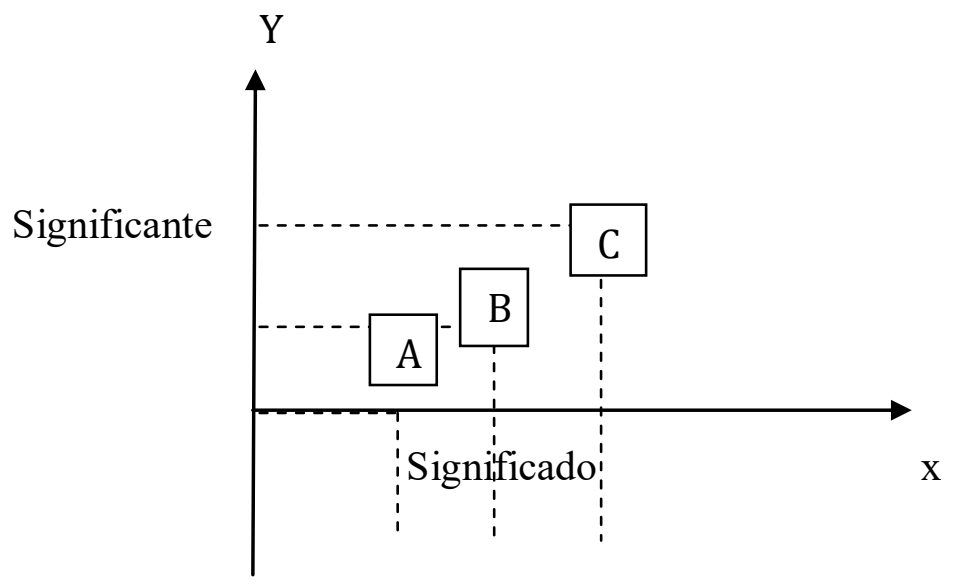

Fonte: Elaboração dos autores.

Para a demonstração da figura 1 pode-se imprimir a seguinte leitura: os pontos A, B e $\mathrm{C}$, identificados no gráfico, representam, cada um deles, a atualização de um acontecimento, efetuado a partir da convergência do significante e do significado, em um enunciado. Disso, a cada vez em que se tem a atualização de um acontecimento (o ponto A, por exemplo), há singularidades que emanam dessa convergência, intrínsecas ao ponto desse encontro (acontecimento efetuado), mas que não são pertencentes às séries, ou seja, a(s) singularidade(s) não pertence $(\mathrm{m})$ nem ao significante e nem ao significado em si, mas ao ressoar dos dois, na efetivação do acontecimento.

Assim, para cada acontecimento, temos a convergência de significantes e significados, que por sua vez, engendram a singularidade do contexto enunciativo, de forma que podemos considerar que os sentidos deslizam a cada enunciação, de acordo com a formação discursiva em que o sujeito está inscrito e com a heterogeneidade marcada nos lugares dessa formação.

A fim de uma exposição mais detalhada do sinalizado nos primeiros parágrafos, segue, na próxima seção, um percurso teórico-metodológico do ingresso da subjetividade na linguagem a partir da perspectiva enunciativa e a abertura para os estudos do discurso. $\mathrm{Na}$ sequência, apresenta-se a proposta central deste trabalho buscando-se mostrar como a singularidade é designada no acontecimento que tem como ponto de emergência o enunciado fruto do ressoar da estrutura determinante. 


\section{DA ENUNCIAÇÃO E DO ENUNCIADO À FORMAÇÃO DISCURSIVA}

Ao tratar da enunciação, recorre-se, principalmente, à Teoria da Enunciação, fundada por Émile Benveniste. É a partir dele que se inicia uma mudança de foco nos estudos linguísticos no tangente à presença da subjetividade na linguagem. Em Problemas de Linguística Geral I, Benveniste (2005) desenvolve reflexões sobe o uso da linguagem verbal. Ao colocar a frase no nível da linguagem em ação, a frase passa do domínio da língua como um sistema de signos, para a língua como materialização no discurso. "A frase, criação indefinida, variedade sem limite, é a própria vida da linguagem em ação" (BENVENISTE, 2005, p.139). Define, então, a frase como unidade do discurso.

Para Benveniste (1989), há um aparelho formal da enunciação (língua e fala simultaneamente). Trata-se de um dispositivo existente nas línguas, disponibilizado pela própria estrutura da língua, para a atualização da fala. O locutor enuncia seu dizer partindo da posição do "eu" e, ao mesmo tempo, remete seu dizer à posição do outro, ou seja, aquele que ocupa a segunda pessoa do discurso, o "tu". Relaciona-se, assim, o emprego da língua à enunciação, uma vez que a enunciação consiste do ato do falante de mobilizar a língua, materializando-a em discurso em forma de enunciado. E, desse modo, uma gama de palavras dêiticas - como os pronomes pessoais, os advérbios de lugar e de tempo - alçam sentidos específicos decorrentes do modo como são mobilizados pelos falantes que integram a enunciação.

Assim, a partir dos estudos da enunciação, abrem-se horizontes para teorias do discurso, que tratam tanto da constituição do sujeito pela/na linguagem quanto do sentido da palavra em uso. A enunciação está na base dos processos discursivos.

Nessa direção, considera-se que há uma movência do sentido do enunciado na produção de um acontecimento, razão pela torna-se fundamental retomar aqui os pressupostos teóricos de Foucault (2002) e de Pêcheux (1997), considerando-se a imbricação dessas formulações àquelas de Deleuze (2009) e de Derrida (1995).

Foucault (2002) propõe uma discussão em torno da unidade constitutiva da formulação do discurso. Para isso parte da necessidade de se diferenciar frase de enunciado. Considera o autor que, devido às várias definições de frase, há de se reconhecer frases que não sejam enunciados, ou enunciados que não sejam frases. Foucault argumenta não existir equivalência total entre ambas as definições, uma vez que a frase está no nível da estrutura gramatical, enquanto o enunciado está no nível do acontecimento.

O enunciado não é uma unidade da mesma ordem da frase. As frases são possibilidades da língua, não são materiais; são virtualidades. Nos termos de Foucault (2002, p.98-99):

\footnotetext{
Em seu modo de ser singular (nem inteiramente linguístico, nem exclusivamente material), ele [o enunciado] é indispensável para que se possa dizer se há ou não frase, proposição, ato de linguagem [...] trata-se de uma função que se exerce verticalmente, em relação às diversas unidades, e que permite dizer, a propósito de uma série de signos, se elas estão aí presentes ou não. [...] ele [o enunciado] não é em si mesmo uma unidade, mas sim uma função que cruza um domínio de estruturas e de unidades possíveis e que faz com que apareçam, com conteúdos concretos, no tempo e no espaço.
}

Acrescenta, ainda, que para que haja um enunciado, não é condição necessária a presença de uma estrutura proposicional definida. Foucault exemplifica: "Ninguém ouviu" e "É verdade que ninguém ouviu", do ponto de vista lógico, não são consideradas duas 
proposições diferentes, trata-se da mesma estrutura proposicional, mas com características enunciativas diferentes, assim, dois enunciados diferentes.

Segundo Foucault (2002, p.94), o enunciado está no plano do discurso, não se submete a uma estrutura linguística constituinte das frases, mas "trata-se da operação efetuada [...] pelo que se produziu pelo próprio fato de ter sido enunciado".

Os enunciados não existem no sentido em que existe uma língua. A língua existe como sistema de construção para possíveis enunciados, pois jamais se apresenta em si própria e em sua totalidade. E os signos que formam os elementos da língua são formas impositivas aos enunciados e os regem internamente. Por um lado, se não houvesse enunciados, a língua não teria existência, por outro, nenhum enunciado é indispensável para a língua existir. Por isso, no lugar de qualquer enunciado pode sempre haver outro enunciado e isso não implica em modificar a língua. (FOUCAULT, 2002, p.96).

Nessa perspectiva pode-se compreender o enunciado como imbricado a um acontecimento. E o acontecimento - materializado em enunciado - vincula-se ao sujeito por meio da atualização do(s) efeitos de sentido de toda a produção de diz(eres). Embora único, o enunciado está aberto à repetição. Mas, convém lembrar que, a cada acontecimento, tem-se um novo enunciado, com sentidos diferentes, já que está ligado à situação e às posições ocupadas pelo sujeito. $\mathrm{O}$ enunciado pode ser entendido como unidade elementar do discurso.

Dessa forma, o discurso materializa-se em enunciados. Foucault (2002, p.132-133) define o discurso como sendo um conjunto de enunciados apoiados pela mesma formação discursiva. O discurso não é uma unidade retórica ou formal repetível indefinidamente cuja utilização poder-se-ia marcar, explicar ou prever na história. Ele é constituído de um número limitado de enunciados definidos por um conjunto de condições de existência.

Diante disso, um enunciado é intrínseco a uma determinada exterioridade (histórica), a uma relação que mantém com quem o enuncia e à formação discursiva a que se filia, ou seja, é inerente às condições em que se realiza. De acordo com Foucault (2002, p.114), "não há enunciado que não suponha outros; não há nenhum que não tenha em torno de si, um campo de coexistências".

Pêcheux (2008) em $O$ discurso: estrutura ou acontecimento discute a relação entre a estrutura do enunciado e o acontecimento no qual ele é proferido. $\mathrm{O}$ autor exemplifica com o enunciado "On a gagné" ["Ganhamos"]; um enunciado tipicamente proferido no âmbito de uma formação discursiva esportiva e que produz uma série de possíveis efetivos de sentido nesse campo. Quando um torcedor de um time de futebol, por exemplo, profere "ganhamos" implica sentidos por aquilo que é dito e por aquilo que deixa de ser dito. "Ganhamos", nesse caso, não significa que ele (o torcedor) jogou e ganhou, mas que seu time assim o fez. Por outro lado, significa, ainda, por meio do não dito que o time adversário saiu derrotado do jogo, e, por consequência, todos os torcedores daquele time. Assim, proferir um "grito de guerra" tal como "ganhamos" implica, mais que anunciar a própria vitória, marcar a derrota do outro.

Pêcheux compara esse mesmo enunciado agora proferido em Paris, em 10 de maio de 1981, quando do resultado das eleições presidenciais naquele país, dando a vitória, em segundo turno, com 52\% dos votos, a François Mitterrand, o primeiro presidente socialista da França. Era a terceira vez que Mitterrand se candidatava à presidência e sua vitória representava uma guinada na política do país, governado por conservadores desde 1958. Pêcheux procura mostrar como esse mesmo enunciado (com uma mesma estrutura) vai ser colado ao acontecimento que esta sendo construído a partir de um fato novo e pelos comentários dos analistas políticos na divulgação do resultado das eleições pela mass-media. Desse modo, o acontecimento começa a se reorganizar em seu contexto de atualidade e espaço de memória. O acontecimento de ocorrência do enunciado é outro, mas retoma um já dito. Nos termos de Pêcheux (2008), "o acontecimento, no ponto de encontro de uma 
atualidade a uma memória" (p.17). Agora no espaço de uma formação discursiva do político constitui a retomada direta "do grito coletivo dos torcedores de uma partida esportiva cuja equipe acaba de ganhar [...] se converte em atividade coletiva gestual e vocal, materializando a festa da vitória da equipe, tanto mais intensamente quanto era mais improvável." (p.21). Assim, há dois sentidos, para um mesmo enunciado. O que determina o sentido é o acontecimento que, por sua vez, filia-se a formações discursivas distintas.

Para Pêcheux (2008, p.53):

[...] todo enunciado é intrinsecamente suscetível de tornar-se outro, diferente de si mesmo, se deslocar discursivamente de seu sentido para derivar para um outro (a não ser que a proibição da interpretação própria ao logicamente estável se exerça sobre ele explicitamente). Todo enunciado, toda sequência de enunciados é, pois, linguisticamente descritível como uma série (léxico-sintaticamente determinada) de pontos de deriva possíveis, oferecendo lugar à interpretação.

Cabe à função enunciativa para que uma frase, uma proposição ou um ato de linguagem se torne um enunciado. Essa função enunciativa é que faz com que o enunciado possa tornar-se outro, na medida em que o sujeito encontra-se em uma posição ou outra. Essa função enunciativa é apontada por Pêcheux $(1997$, p.160) ao tratar do sentido das palavras relacionado à posição ocupada pelo sujeito, determinada por regras sócio-históricas, uma vez que o sentido não existe em si mesmo; "as palavras, expressões, proposições, etc., mudam de sentido segundo as posições sustentadas por aqueles que as empregam". Esclarece que o sentido surge em referência a essas posições, ou seja, emergem no bojo das formações ideológicas nas quais essas posições se inscrevem.

Os processos discursivos que emanam da enunciação não têm sua origem no sujeito, mas se efetuam nele, em enunciados únicos. Embora pareça contraditório, essa operação implica diretamente na constituição do sujeito e no seu assujeitamento frente às condições de produção dos enunciados: de um lado, o efeito do lugar e da posição em que advém o enunciador, do outro, a situação empírica do enunciador nesse lugar, isto é, o ambiente material e os papéis que estão em jogo na interlocução. Dito de outro modo, a história desse sujeito que ocupa um espaço em um determinado tempo incide sobre o ato de/para dizer.

Votando a Foucault (2002), pode-se afirmar que o enunciador ocupa uma determinada posição, a partir de um lugar, e essa possibilidade/capacidade (de ocupar posições) é que lhe constitui como sujeito, ou seja, o sujeito é o sujeito do discurso.

Já em Pêcheux e Fuchs (2010), o fato de o sujeito assumir o discurso como seu produz a ilusão de ele ser a fonte de seu próprio discurso e de controlar o sentido daquilo que diz.

[...] definimos a enunciação como a relação sempre necessariamente presente do sujeito enunciador com o seu enunciado, então aparece claramente, no próprio nível da língua, uma nova forma de ilusão segundo a qual o sujeito se encontra na fonte do sentido ou se identifica à fonte do sentido: o discurso do sujeito se organiza por referência (direta, divergente), ou ausência de referência, à situação de enunciação (o "eu-aqui-agora"do locutor) que ele experimenta subjetivamente como tantas origens quantos são os eixos de referenciação (eixo das pessoas, dos tempos, das localizações). (PÊCHEUX \& FUCHS, 2010, p.169).

Tem-se que os processos de enunciação se realizam em enunciados que se constituem pelo dito e pela negação ao não dito. A ilusão do sujeito está exatamente na impressão de que seu dizer lhe é peculiar e único, ao invés de compreender que tudo sempre 
já está lá, na transcendência que inspira e, ao mesmo tempo, produz o dizer do sujeito, possibilitando a seleção de um e não de outro enunciado.

Pêcheux e Fuchs (2010, p.175) propõem "chamar este efeito de ocultação parcial esquecimento número 2 e de identificar aí a fonte da impressão de realidade do pensamento para o sujeito ("eu sei o que eu digo", "eu sei do que eu falo")". Assim, os enunciados são produzidos a partir de esquecimentos, ou seja, da seleção de um dizer e do apagamento de outros dizeres/sentidos (esquecimento número 2). O sujeito tem a ilusão de que o que foi dito surgiu no momento do dizer e acredita revelar seus mais profundos pensamentos, desprezando as filiações de sentido associadas a sua posição, numa dada formação discursiva. É justamente esse apagamento que cria o efeito de unicidade do dizer, de que algo só poderia ter sido dito daquela maneira e não de outra.

A outra ilusão, identificada pelos autores de esquecimento número 1, está intimamente ligada à formação discursiva a qual se filia o sujeito, ou seja, o enunciado tem seu sentido inscrito numa determinada formação discursiva, indicando que o dizer não é dele (do indivíduo), mas de um sujeito interpelado pela ideologia que caracteriza uma determinada formação, no entanto o sujeito não tem consciência disso e profere colocando-se como fonte e origem de seu dizer.

Pêcheux e Fuchs (2010, p.178) apontam uma relação e um diferencial entre esses dois esquecimentos, sendo "preciso não perder de vista que o recalque que caracteriza o 'esquecimento número 1' regula, afinal de contas, a relação entre dito e não dito no 'esquecimento número 2', onde se estrutura a sequência discursiva." Isto posto conforme a formulação de Lacan de que todo discurso é ocultação do inconsciente.

O sujeito não é indivíduo, empírico, mas é sujeito do discurso. E apesar de ter a ilusão de ser a origem do dizer e de controlar o sentido do que diz, ele é, segundo Pêcheux (1997), preenchido por aquilo que o autor designa como forma-sujeito: "a forma-sujeito tende a absorver-esquecer o interdiscurso no intradiscurso, isto é, ela simula o interdiscurso no intradiscurso, de modo que interdiscurso aparece como "já-dito" do intradiscurso, no qual se articula por "co-referência". (PÊCHEUX, 1997, p.167). Em outras palavras, a forma-sujeito incorpora o interdiscurso e produz no sujeito um efeito ilusório de unidade e homogeneidade.

Pêcheux (1997, p.266) retoma uma citação posta na conclusão do texto redigido em 1975: "a forma-sujeito do discurso, na qual coexistem, indissociavelmente, interpelação, identificação e produção de sentido, realiza o non-sens da produção do sujeito como causa de si sob a forma da evidência primeira" para mostrar que o sentido é produzido pela relação que o sujeito estabelece com a forma-sujeito, esta, por sua vez, associada a uma formação discursiva específica.

Nota-se, então, que o sujeito na perspectiva discursiva constitui-se em meio a uma contradição: é ao mesmo tempo livre e submisso. Livre para dizer tudo desde que se submeta ao que está base do assujeitamento: a língua. Decore, assim, uma tênue - e nem sempre clara - diferença entre o que se identifica como forma-sujeito e posição-sujeito. A primeira é aquela pela qual a história determina - e não há como escapar - um modo de o indivíduo ser interpelado em sujeito ao assumir uma determinada posição-sujeito. Por outro lado, a segunda, também constituída sócio-historicamente, tem sua função regular a produção de dizer do sujeito quando este ocupa um determinado lugar no discurso como sendo o seu. Em uma sociedade capitalista, por exemplo, não há como "escapar" da forma-sujeito-capitalista; o indivíduo é submetido ao dispositivo jurídico que rege esse sistema, sendo assim interpelado em sujeito pelo próprio sistema. Porém, pode assumir uma posição-sujeito contrária aos ideais do capitalismo, constituindo-se, no âmbito de uma formação discursiva socialista.

O sujeito do discurso, ao enunciar, o faz pela identificação com a forma-sujeito, estabelecida pelos saberes de uma determinada formação discursiva. Courtine (1982, p.252) parece concordar com essa perspectiva de Pêcheux e propõe que se pense a "descrição de um 
conjunto de diferentes posições-sujeito em uma dada formação discursiva como modalidades particulares de identificação do sujeito da enunciação com o sujeito do saber, considerando os efeitos discursivos específicos que aí se relacionam."

Já em Foucault (2002, p.43), é a partir do próprio enunciado que o autor trata da noção de formação discursiva, uma vez que não leva em consideração a imbricação das formações ideológicas e a própria noção de ideologia na constituição do sujeito:

[...] no caso em que se puder descrever, entre um certo número de enunciados, semelhantes sistema de dispersão, e no caso em que entre os objetos, os tipos de enunciação, os conceitos, as escolhas temáticas, se puder definir uma regularidade (uma ordem, correlações, posições e funcionamentos, transformações), diremos, por convenção, que se trata de uma formação discursiva.

Segundo Foucault (2002), as regularidades discursivas, no sentido da ordem, da correlação, determinam um princípio organizador que caracteriza certa homogeneidade e fechamento de uma formação discursiva. A noção de formação discursiva, à qual se refere Foucault (2002), é justamente marcada a partir de certas regularidades que não podem ser observadas de uma forma descritiva quantitativa, mas que são constituintes das condições de produção do discurso, ou seja, diz respeito a espaço social e à história, num movimento ininterrupto e descontínuo do tempo.

A leitura que Fernandes (2012, p.23) faz de Foucault aponta que todo discurso constitui-se da dispersão de acontecimentos e discursos variados que se transformam e se modificam. Assim, uma dada formação discursiva consiste de elementos advindos de outras formações discursivas, por vezes, até contraditórias. Por isso, para Foucault, todo discurso é marcado por enunciados que o antecedem e o sucedem e tem como característica a contradição.

Foucault também refletiu acerca das transformações a que estão sujeitas as formações discursivas, lembrando que, mesmo sendo dinâmicas, elas mantêm as suas regularidades de forma substantiva. Ele afirma que a formação discursiva não desempenha um papel estático por décadas ou séculos "ela determina uma regularidade própria a processos temporais; coloca princípios de articulação entre uma série de acontecimentos discursivos e outra série de acontecimentos, de transformações, de mutações e de processos. (FOUCAULT, 2002, p.90). Por isso, o autor não a vê como uma forma intemporal, ao contrário, vislumbra um esquema de correspondência entre diversas séries temporais.

Cabe também explicitar que tipo de regularidade é essa que caracteriza tão fortemente uma formação discursiva, segundo o que o próprio Foucault (2002, p.51, grifos do autor) compreende:

No caso em que se pudesse descrever [...] semelhante sistema de dispersão, no caso em que entre os objetos, os tipos de enunciação, os conceitos, as escolhas temáticas, se poderia definir uma regularidade (uma ordem, correlações, posições e funcionamentos, transformações), dir-se-á, por convenção, que se trata de uma formação discursiva - evitando, assim, palavras demasiado carregadas de condições e consequências, inadequadas, aliás, para designar semelhante dispersão, como "ciência", ou "ideologia" ou "teoria", ou domínio de objetividade. Chama-se-se-á regras de formação às condições a que estão submetidos os elementos dessa repartição.

A partir do excerto, ressalta-se o que se disse anteriormente como marca de uma diferença na formulação foucaultiana em que o autor se distancia - por uma escolha teórica e 
metodológica - da noção de ideologia como princípio organizador de uma formação discursiva.

Marcar essa diferença é importante para se compreender que apesar das similitudes, o ponto nodal do qual parte Pêcheux e Foucault é distinto. Já a partir das primeiras formulações de Pêcheux, a respeito de formação discursiva, em um texto em parceria com Fuchs (PÊUCHEUX \& FUCHS, 2010, grifo dos autores), é possível se observar a convergência da relação entre ideologia e discurso, conforme descreve o fragmento abaixo:

\begin{abstract}
Se deve conceber o discursivo como um dos aspectos materiais do que chamamos de materialidade ideológica. Dito de outro modo, a espécie discursiva pertence ao gênero ideológico, o que é o mesmo que dizer que as formações ideológicas comportam necessariamente, como um de seus componentes, uma ou várias formações discursivas interligadas que determinam o que pode e deve ser dito, a partir de uma posição dada numa conjuntura, isto é, numa relação de lugares no interior de um aparelho ideológico. (PÊUCHEUX \& FUCHS, 2010, p.166-167).
\end{abstract}

Para Pêcheux (1997), os enunciados discursivos, que emergem de uma dada formação discursiva, caracterizam-se por um modo de relacionar-se com a ideologia vigente, indicando o que pode e o que não pode ser dito. É a partir da exterioridade da formação discursiva que as regularidades são instituídas e o conjunto do dizível é delimitado, com base numa perspectiva histórica e linguística. Pêcheux (1997, p.160) chama de formação discursiva "aquilo que, numa formação ideológica dada, determinada pelo estado da luta de classes, determina o que pode e deve ser dito (articulado sob a forma de uma arenga, de um sermão, de um panfleto, de uma exposição, de um programa, etc.)".

Por isso, a noção de sujeito, para Pêcheux, está intimamente ligada à noção de formação discursiva. Segundo ele, "os indivíduos são interpelados em sujeitos de seu discurso, pelas formações discursivas que representam "na linguagem" as formações ideológicas que lhes são correspondentes". (PÊCHEUX, 1997, p.161). Assim, tem-se em Pêcheux, ao contrário de Foucault, uma imbricação de sobreposição entre ideologia e discurso.

Até este ponto discutiu-se as abordagens teóricas em torno do enunciado como materialidade no discurso na enunciação. E, assim, sinalizou-se como a partir da noção de ideologia (Pêcheux) e enunciado (Foucault) chega-se à compreensão de formação discursiva. Contudo, este artigo tem o objetivo de designar a singularidade do acontecimento, efetuado no enunciado, a partir do ressoar da estrutura que o determina, razão pela qual se discutirá a esse respeito na próxima seção.

\title{
3 A ESTRUTURA E 0 ACONTECIMENTO: 0 RESSOAR DA SINGULARIDADE
}

Conforme sinalizado na introdução, para Deleuze (2009), há duas condições mínimas para que se instaure uma estrutura.

Primeiramente é necessário que se tenha duas séries heterogêneas - identificadas como significante e significada -, sendo que à série significante Deleuze atribui o oportuno adjetivo: "flutuante". Observa-se, nesse ponto, uma aproximação do que Deleuze considera significante com o que Pêcheux chama de pré-construído, ou seja, a virtualidade (Deleuze) sempre "já lá" (Pêcheux), que fornece possibilidades de sentidos e também de acontecimentos múltiplos.

Pode-se, segundo Pêcheux (1997, p.156), considerar o pré-construído "como a modalidade discursiva da discrepância pela qual o indivíduo é interpelado em sujeito... ao 
mesmo tempo em que é 'sempre-já sujeito"'. A discrepância, explica o autor, que consiste entre a estranheza familiar de um fora situado antes, em outro lugar, e o sujeito identificável e responsável por seus atos, funciona por contradição, quer o sujeito se submeta a ela ou não. Logo, pode-se inferir, em Pêcheux, o pré-construído como o lugar da virtualidade do interdiscurso, ou seja, o campo em que todas as possibilidades de dizeres estão dispostas para se instaurarem em enunciados, determinados pelas posições que o sujeito assume ao dizer, conforme as formações discursivas e a historicidade que caracterizam as enunciações na emergência de um acontecimento. Especificamente quanto ao interdiscurso, Pêcheux (1997, p.167) o identifica como discurso-transverso, pois atravessa e conecta elementos discursivos constitutivos pelo interdiscurso enquanto pré-construído e fornece as condições para o sujeito se constituir como "sujeito falante", conforme a formação discursiva à qual se assujeita; e que, aqui, prefere-se dizer: à qual se filia.

A segunda condição para a instauração da uma estrutura, conforme Deleuze, consiste no fato de que cada uma dessas séries - significante e significada - é composta por termos que, a priori, não existem, mas passam a ter suas existências marcadas a partir do momento em que se relacionam e se instauram discursivamente. É exatamente no ponto em que as relações entre as séries significante e significada se estabelecem que se atualizam os acontecimentos, marcados por singularidades muito particulares, conforme já demonstrado na figura 1.

A estrutura é, portanto, condição para a identificação de uma formação discursiva, num jogo de presença e ausência, dada a infinitude da potência (presença - significante) que tende a suprir qualquer falta (ausência - significado). Além disso, no momento em que se atualiza em acontecimento, renovam-se outras faltas sucessivas (outros não ditos), produzindo, assim, efeitos de sentido em cada acontecimento atualizado (na emergência do que foi dito).

Esse jogo da presença e da ausência está diretamente relacionado com a equivalência substitutiva entre o virtual e o real (real entendido como efeito do acontecimento). Enquanto ausência, a potência (de sentido) permanece na virtualidade; enquanto presença, traduz-se em função da atualização dessa potência, que produz um efeito de sentido no acontecimento, dado na enunciação.

Afirma-se, então, que, a série significante representa todas as possibilidades da língua, enquanto a série significada representa as "totalidades produzidas" (DELEUZE, 2009, p.51). Para que uma estrutura se efetive, é necessário que essas séries diferentes sejam determinadas em um acontecimento.

No livro A escritura e a diferença, Jacques Derrida (1995) denomina essa relação que se estabelece entre as séries - significante e significada - de jogo da estrutura. Segundo Derrida (1995, p.230), para se estabelecer um acontecimento ocorre um jogo na estrutura, de modo que "é certo que o centro de uma estrutura, orientando e organizando a coerência do sistema, permite o jogo dos elementos no interior da forma total". Isso porque por mais contraditório que possa parecer o centro da estrutura está na estrutura e fora da estrutura. "Está no centro da totalidade e contudo, dado que o centro não lhe pertence, a totalidade tem $o$ seu centro noutro lugar (grifos do autor)."

De acordo com Derrida (1995), há que se buscar a origem da estrutura, antes mesmo do que define a própria episteme, isto é, a ciência e a filosofia ocidental, e mergulhar no que considera a raiz de toda a estrutura, qual seja a estruturalidade. Em outros termos, para o autor, a possibilidade do jogo estrutural está antes da própria estrutura, ao que se opta aqui por nomear essa estruturalidade de arquiestrutura, isto é, a possibilidade - antes - de se instaurar uma estrutura. Essa potência de instauração da estrutura é o que torna possível o vibrar da própria estrutura. 
Figura 2 - A arquiestrutura como possibilidade para a estrutura

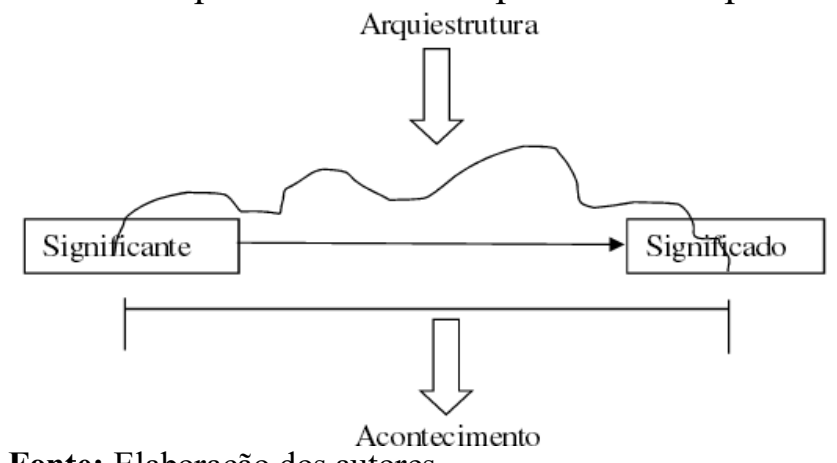

Fonte: Elaboração dos autores.

A estruturalidade anterior à estrutura não tem somente a função de organizar o jogo, mas, sobretudo, de limitar a sua atualização, de permitir que no auge da sua transcendência, seja potência para o jogo. Nos termos de Derrida, o centro da estrutura representa o próprio impensável, ao que se acrescenta: dentro do espectro - da arquiestrutura - do que pode ser pensado.

Desse modo, está se chamando de arquiestrutura a potência que provoca e permite o jogo entre as séries significante e significada se instaurar. E, por assim dizer, está além da e, sobretudo, posta antes da própria estrutura, tendo sua atualização no acontecimento que identifica certa estrutura. Já o acontecimento é a efetivação de uma presença (antes virtualidade) em atualizações diversas e ao mesmo tempo únicas (de significados), que determinam o efeito de real na materialização do enunciado.

Há sempre um devir que, em essência, não tem, necessariamente, uma relação com o passado ou com o futuro - aion: ideia de duas eras -, ou seja, é atualização pura num nãotempo, que marca uma diferença subjetiva entre os sujeitos: ele não é o mesmo que efetuou um acontecimento, ele é sempre outro, a partir das sucessivas efetuações.

Segundo Deleuze (2009, p.103), "se a batalha não é um exemplo de acontecimento entre outros, mas o Acontecimento na sua essência, é sem dúvida porque ela se efetua de muitas maneiras ao mesmo tempo e que cada participante pode captá-la em um nível de efetuação diferente no seu presente variável". O autor traz essa consideração para pensar nos sentidos que podem emergir e naquele que de fato se instaura em sua gênese produtiva.

É por isso que o acontecimento não pode ser atualizado senão pela vontade própria inspiradora do enunciado daquele que se põe a dizer; pela sua neutralidade com relação a todas as efetuações temporais, mas não neutralizado pelo enunciador, uma vez que a batalha nunca é presente, estando "sempre ainda por vir e já passada" (DELEUZE, 2009, p.103), no que tange à sua efetuação.

Por sua vez, a singularidade é um campo transcendente de energia potencial que se distribui entre as séries (significante e significada) e que se atualiza em um acontecimento, na efetuação de uma cena enunciativa, justamente porque é pré-individual. Não está no sujeito, mas está na enunciação.

Como se atualiza em um acontecimento, a singularidade é neutra, tais são as variações de atualizações que se pode ter em diferentes efetuações nos sujeitos de uma enunciação. Por outro lado, e também por decorrência da sua neutralidade, ela é energia potencial que sobrevoa as dimensões da significação, e que está "sobre uma superfície inconsciente e goza de um princípio móvel imanente de auto-unificação por distribuição 
nômade, que se distingue radicalmente das distribuições fixas e sedentárias como condições das sínteses de consciência." (DELEUZE, 2009, p.105).

Essa "distribuição nômade", a qual se refere Deleuze (2009), explica justamente a energia potencial de uma singularidade de se atualizar em acontecimentos múltiplos, tal a multiplicidade de sujeitos que, inconscientemente, deixam-se atualizar por suas efetuações.

A singularidade é, portanto, o campo de limitação do sentido. Mas a questão é saber como esse campo transcendente é determinado. Escusa-se pela longa citação de Deleuze (2009, p.108) para pontuar-se nos próprios termos do autor a elação da forma pura de consciência da individuação singular do dizer:

\begin{abstract}
Parece-nos impossível lhe dar, à maneira Kantiana, a forma pessoal de um Eu, de uma unidade sintética de a percepção, mesmo se conferimos a esta unidade um alcance universal; [...]. Mas não é, igualmente, possível conservar-lhe a forma de uma consciência, mesmo se definimos esta consciência impessoal por intencionalidades e retenções puras que supõem ainda centros de individuação.[...] A dupla série do condicionado, isto é, da consciência empírica e de seus objetos, deve pois ser fundada numa instância originária que retém a forma pura da objetividade (objeto $=\mathrm{X}$ ) e a forma pura da consciência e que constitui aquela a partir desta. [...] $\mathrm{O}$ que é comum à metafísica e à filosofia transcendental é primeiramente esta alternativa que elas nos impõem ou um fundo indiferenciado, sem-fundo, não-ser informe, abismo sem diferenças e sem propriedades.
\end{abstract}

Enquanto o sentido é posto como originário e predicável, pouco importa saber se é um sentido transcendental e divino esquecido pelo homem ou um sentido puramente humano apartado de Deus. O que está em jogo é que fora da pessoa e do indivíduo nada será distinguido. Por isso a descoberta de Nietzsche está em outro lugar quando explora um mundo de singularidades impessoais e pré-individuais, mundo que chama de dionísico relacionado à vontade de potência, energia livre e não ligada. Singularidades nômades não são mais aprisionadas na individualidade fixa do Ser infinito (Deus) nem do sujeito finito (homem). (DELEUZE, 2009, p.109). Dadas essas considerações, o autor faz questão de enfatizar que a singularidade é uma "máquina dionísica de produzir o sentido e em que o não-senso e o sentido não estão mais numa oposição simples, mas copresentes um ao outro em um novo discurso." (DELEUZE, 2009, p.110).

A verdade é que, por inferência, tanto Deleuze (2009) quanto Pêcheux (1997), seja no campo da Filosofia ou da Análise do Discurso, respectivamente, parecem convergir para a compreensão de que há uma energia potencial que se instaura na enunciação e que se atualiza no acontecimento, por efeito de uma singularidade (no caso de Deleuze (2009)) ou de um sentido (no caso de Pêcheux (1997)) e que se encarna no indivíduo por consequência da sua posição discursiva.

\title{
4 CONDISERAÇÕES SINGULARES
}

Este artigo buscou refletir acerca da estrutura e do acontecimento numa interface das formulações de Gilles Deleuze, Michel Pêcheux e Michel Foucault, em função da designação da singularidade que emana dos acontecimentos, efetuados na enunciação (Benveniste), considerando, ainda, a possibilidade de instauração do acontecimento e do enunciado em vista previsto pelo que Derrida chama de estruturalidade e que aqui se nomeia arquiestrutura.

A partir disso, buscou-se em Foucault (2002) a fundamentação para o enunciado, diferenciando-o da frase, a partir da perspectiva de que ele (o enunciado) não existe no sentido em que existe uma língua. A língua existe como sistema de construção para possíveis 
enunciados. Conforme Foucault (2002, p.94), o enunciado está no plano do discurso, não se submete a uma estrutura linguística constituinte das frases, mas "trata-se da operação efetuada [...] pelo que se produziu pelo próprio fato de ter sido enunciado".

Os enunciados, por sua vez, são repetíveis, enquanto estrutura linguísticas, porém, seu sentido será sempre outro, já que também é sempre outra a emergência daquilo que atualiza acontecimento e enunciado.

Para cada acontecimento atualizado, efetuado a partir da convergência entre potência (significante) e atualização (significado), há singularidades que emanam e que ocupam o lugar do sentido, ou seja, um signo não tem sentido até que ocupe um lugar na superfície, até que se atualize. "Os signos permanecem desprovidos de sentido enquanto não entram na organização de superfície que assegura a ressonância entre as duas séries" (DELEUZE, 2009, p.107). Portanto, a singularidade é energia potencial para a efetuação de sentido em um acontecimento.

Assim, conforme afirma Deleuze (2009, p.119), "cada pessoa é único membro de sua classe e, no entanto, é uma classe constituída pelos mundos, possibilidades e indivíduos que lhe cabem."

Cabe lembrar que, para Pêcheux (1997), esses "mundos" seriam as formações discursivas pelas quais desliza o sujeito na sua história e em sua formação ideológica.

Do exposto neste artigo tem-se a singularidade como o efeito de real a partir do ressoar entre a estrutura e do acontecimento. Fito de outro modo, a singularidade está justamente na efetivação do acontecimento, atualizando-o em um contínuo incessante, mas, por outro lado, evadindo-se dele e se prolongando a outros acontecimentos descontínuos.

\section{REFERÊNCIAS}

BENVENISTE, Émile. Problemas de linguística geral II. Campinas: Pontes, 1989.

Problemas de linguística geral I. 5. ed. Campinas: Pontes, 2005.

COURTINE, Jean-Jacques. Définition d'orientations théoriques et construction de procédures en analyse du discours. Philosophiques, vol. IX, número 2, octobre, 1982.

DELEUZE, Gilles. Lógica do sentido 5. ed. São Paulo: Perspectiva, 2009.

DERRIDA, Jacques. A escritura e a diferença. 2. ed. São Paulo: Perspectiva, 1995.

FERNANDES, Claudemar Alves. Discurso e sujeito em Michel Foucault. São Paulo: Intermeios, 2012.

FOUCAULT. M. A arqueologia do saber. 6. ed. Rio de Janeiro: Forense Universitária, 2002.

PÊCHEUX, Michel. Semântica e discurso: uma crítica à afirmação do óbvio. 3. ed. Campinas: UNICAMP, 1997.

O discurso: estrutura ou acontecimento. 5.ed. Campinas: Pontes, 2008. 
PÊCHEUX, Michel; FUCHS, Catherine. A propósito da análise automática do discurso: atualização e perspectivas. In: GADET, Françoise; HAK, Tony. (org.). Por uma análise automática do discurso. Campinas: UNICAMP, 2010.

Recebido em: 04 de julho de 2016.

Aceito em: 18 de março de 2017. 